\title{
Immunoblasts to Lymphocytes Ratio Measurement
}

National Cancer Institute

\section{Source}

National Cancer Institute. Immunoblasts to Lymphocytes Ratio Measurement. NCI

Thesaurus. Code C106535.

The determination of the ratio of immunoblasts compared to all lymphocytes present in a sample. The measurement may be expressed as a ratio or percentage. 